\title{
Lubiprostone stimulates small intestinal mucin release
}

\author{
Robert C De Lisle
}

\begin{abstract}
Background: Lubiprostone is a synthetic bicyclic fatty acid derivative of prostaglandin E1 $\left(\mathrm{PGE}_{1}\right)$ used for chronic constipation. The best known action of lubiprostone is simulation of $\mathrm{Cl}^{-}$dependent fluid secretion. In a mouse model of the genetic disease cystic fibrosis, we previously showed that in vivo administration of lubiprostone resulted in greater mucus accumulation in the small intestine. The aim of this study was to directly test whether lubiprostone stimulates intestinal mucin release.
\end{abstract}

Methods: Mucin release was measured by mounting segments $(4-5 \mathrm{~cm})$ of mouse proximal-mid small intestine in an organ bath, allowing access to the perfusate (luminal) and the bath (serosal) solutions. Nifedipine $\left(10^{-6} \mathrm{M}\right)$ and indomethacin $\left(10^{-5} \mathrm{M}\right)$ were included in all solutions to inhibit smooth muscle activity and endogenous prostaglandin production, respectively. The tissue was equilibrated under flow for 30 min, using the perfusate collected during the final $10 \mathrm{~min}$ of the equilibration period to measure unstimulated release rate. Stimulus was then added to either the perfusate or the bath and the perfusate was collected for another 30 min to measure the stimulated mucin release rate. Mucin in perfusates was quantified by periodic acid-Schiff's base dot-blot assay, using purified pig gastric mucin as a standard.

Results: When applied luminally at $1 \mu \mathrm{M}$ lubiprostone was ineffective at stimulating mucin release. When added to the serosal solution, $1 \mu \mathrm{M}$ lubiprostone stimulated mucin release to $\sim 300 \%$ of the unstimulated rate. As a positive control, serosal $1 \mu \mathrm{M}$ prostaglandin E2 increased mucin release to $400 \%$ of the unstimulated rate.

Conclusions: These results support the idea that lubiprostone has prostaglandin-like actions on the intestine, which includes stimulation of mucin release. Stimulation of mucin release by lubiprostone may be protective in gastrointestinal conditions where loss of mucus is believed to contribute to pathogenesis. Thus, in addition to chronic constipation, there is greater potential for the therapeutic applications of lubiprostone.

Keywords: Intestine, Lubiprostone, Mucin, Prostaglandin

\section{Background}

Lubiprostone is a synthetic bicyclic fatty acid derivative of prostaglandin E1 used for chronic constipation. The best known action of lubiprostone is simulation of $\mathrm{Cl}$ dependent fluid secretion. The originally proposed mechanism of lubiprostone is activation of the CLC2 chloride channel but this is controversial [1]. Recent work suggests that lubiprostone may act in a prostaglandin-like manner to stimulate cystic fibrosis transmembrane conductance regulator (CFTR) dependent $\mathrm{Cl}$ - and fluid secretion [2].

Correspondence: rdelisle@kumc.edu

Anatomy and Cell Biology, University of Kansas School of Medicine, Kansas City, KS 66160, USA
In the genetic disease cystic fibrosis (CF) there is impaired $\mathrm{Cl}^{-}$and fluid secretion by affected epithelia contributing to the pathophysiology in this disease. Because lubiprostone can stimulate $\mathrm{Cl}^{-}$secretion, we had previously investigated its use as a therapy for CF by testing its effects in a mouse model of CF, a Cftr knockout [3]. Treatment of CF mice with lubiprostone did ameliorate some of the CF related alterations. Lubiprostone treatment of CF mice accelerated gastric emptying, decreased small intestinal bacterial overgrowth, and reduced inflammation. These effects are independent of lubiprostone's ability to stimulate $\mathrm{Cl}^{-}$secretion because intestinal tissue from CF mice does not secrete $\mathrm{Cl}^{-}$in response to lubiprostone [2]. Unexpectedly, in vivo administration of lubiprostone to 
CF mice resulted in greater mucus accumulation in the small intestine [3], mucus accumulation being one of the major phenotypes of CF. This effect on mucus accumulation is consistent with lubiprostone acting through a prostaglandin receptor, as prostaglandin $\mathrm{E} 2\left(\mathrm{PGE}_{2}\right)$ is a known potent stimulus for intestinal mucin release. Therefore, in this project we investigated the ability of lubiprostone to stimulate mouse intestinal mucin secretion, using an ex vivo organ bath approach.

\section{Methods}

Measurement of intestinal mucin release using an ex vivo system

Mucin released was measured similar to that described in [4]. Male C57BL/6 J mice (Jackson Labs, Bar Harbor, $\mathrm{ME})$ were used at 10-12 weeks of age. All animal work was approved by the Institutional Animal Care and Use Committee of the University of Kansas Medical Center. Mice were killed by $\mathrm{CO}_{2}$ asphyxiation and cervical dislocation. The small intestine was removed into ice cold phosphate buffered saline (PBS) containing nifedipine $\left(10^{-6} \mathrm{M}\right)$ and indomethacin $\left(10^{-5} \mathrm{M}\right)$ to inhibit smooth muscle activity and endogenous prostaglandin production, respectively. After discarding the proximal most $4 \mathrm{~cm}$ of the small intestine, the next two adjacent segments of 4-5 cm of intestine (jejunum) were dissected from each mouse. The number of segments reported as (n) in the figure legends indicates the number of mice used. These segments were mounted by securing with thread at either end to fire-polished $1.2 \mathrm{~mm}$ diameter glass capillaries (see Figure 1). A stainless steel tissue holder (Biopac, Goleta, CA; catalog RXHOLDER-S) was modified to accept one of the glass capillaries by attaching a pair of plastic connectors (Cole-Parmer, Chicago, IL; kit \#6365-90; $1.6 \mathrm{~mm}$ elbows) to one another by short pieces of tubing and epoxying them to the rod to make a U-shaped connector at the bottom (Figure 1). The other end of the U-shaped connector was attached to sylastic tubing through a peristaltic pump (Fisher Scientific, catalog 13-876-1) set to achieve a flow rate of $\sim 0.2 \mathrm{~mL} \mathrm{~min}^{-1}$. The outflow tubing, attached to the upper glass capillary, was positioned about $1 \mathrm{~cm}$ above the upper level of the tissue to maintain a slight positive pressure in the segment to keep the lumen open. The lumen perfusate solution was PBS without glucose, warmed to $37^{\circ} \mathrm{C}$. The mounted tissue was placed vertically in an organ bath $(20 \mathrm{~mL}$; Biopac). The bath was filled with bicarbonate buffered Ringer's solution containing $10 \mathrm{mM}$ glucose, continuously gassed with 95\% $\mathrm{O}_{2} / 5 \% \quad \mathrm{CO}_{2}$, and thermostated to $37^{\circ} \mathrm{C}$. Nifedipine $\left(10^{-6}\right)$ and indomethacin $\left(10^{-5}\right)$ were included in all solutions. The tissue was equilibrated under flow $\left(\sim 0.2 \mathrm{~mL} \mathrm{~min}{ }^{-1}\right)$ for $30 \mathrm{~min}$. The perfusate collected during the final $10 \mathrm{~min}$ of the equilibration period was used to measure the unstimulated release rate. Stimulus was then added to either the perfusate solution or the bath solution, and the perfusate outflow was collected for another $30 \mathrm{~min}$. The perfusate outflow during this latter period was used to measure the stimulated mucin release rate.

\section{Quantification of released mucins}

Mucin in perfusates was quantified by periodic acidSchiff's base dot-blot assay, using a kit (Sigma; catalog 395B). Pig gastric mucin (Sigma, St. Louis, MO; catalog M1778) was used as a standard, prepared by suspension at $10 \mathrm{mg} \mathrm{mL}^{-1}$ in PBS using a probe-type sonicator. Serial 2-fold dilutions were prepared and in each assay $125 \mu \mathrm{g}$ through $0.122 \mu \mathrm{g}$ of mucin plus a blank were applied by vacuum filtration to nitrocellulose membrane in a dot-blot apparatus (Bio-Rad, Hercules, CA). A standard series of gastric mucins was included on every dotblot. Perfusate outflow samples $(50 \mu \mathrm{L})$ were applied in duplicate to the membrane as well. The membrane was removed from the apparatus and sequentially incubated in $3 \%$ acetic acid for $10 \mathrm{~min}, 6 \mathrm{X}$ diluted periodic acid for $15 \mathrm{~min}, 3 \%$ acetic acid washing for $10 \mathrm{~min}, 6 \mathrm{X}$ diluted Schiff's Reagent for $10 \mathrm{~min}, 5 \mathrm{mg} \mathrm{mL}^{-1}$ sodium metabisulfite in water for $10 \mathrm{~min}$, rinsing in water for $10 \mathrm{~min}$, followed by air drying. The dried blots were scanned with a flatbed scanner (Hewlett Packard, Palo Alto, CA) and relative intensities measured using OptiQuant software (Kodak, Rochester, NY). The standard curve data were analyzed and sample unknowns determined using SigmaPlot software (Jandel Scientific, San Jose, CA; 'Standard Curves' feature in the 'Pharmacology' menu, with 'Log X-scale' and 'Predict unknowns'). The PeakFit program (Jandel Scientific) was used to determine area under the curve (AUC) for 20-30 time points (unstimulated), and the 30-60 min time points (stimulated) which are presented as $\mu \mathrm{g}$ mucin $\min ^{-1} \mathrm{~g}^{-1}$ tissue.

\section{Statistical analysis}

Data are presented as means \pm standard errors. When there are 2 groups of data, a $t$-test was used. When there are more than 2 groups an ANOVA with post-hoc Tukey's test was used. P-values $<0.05$ are considered statistically significant.

\section{Results and discussion}

To measure mucin release from mouse small intestine, an ex vivo perfusion system was established similar to that in [4] using modifications as described in the Methods (Figure 1). It is assumed that with an adequate flow rate and the presence of bicarbonate ion in the perfusate and bath solutions, that the exocytosed mucins will expand and be mobile enough to be quantitatively included in the perfusate [4]. Mucin in perfusate outflow was quantified 


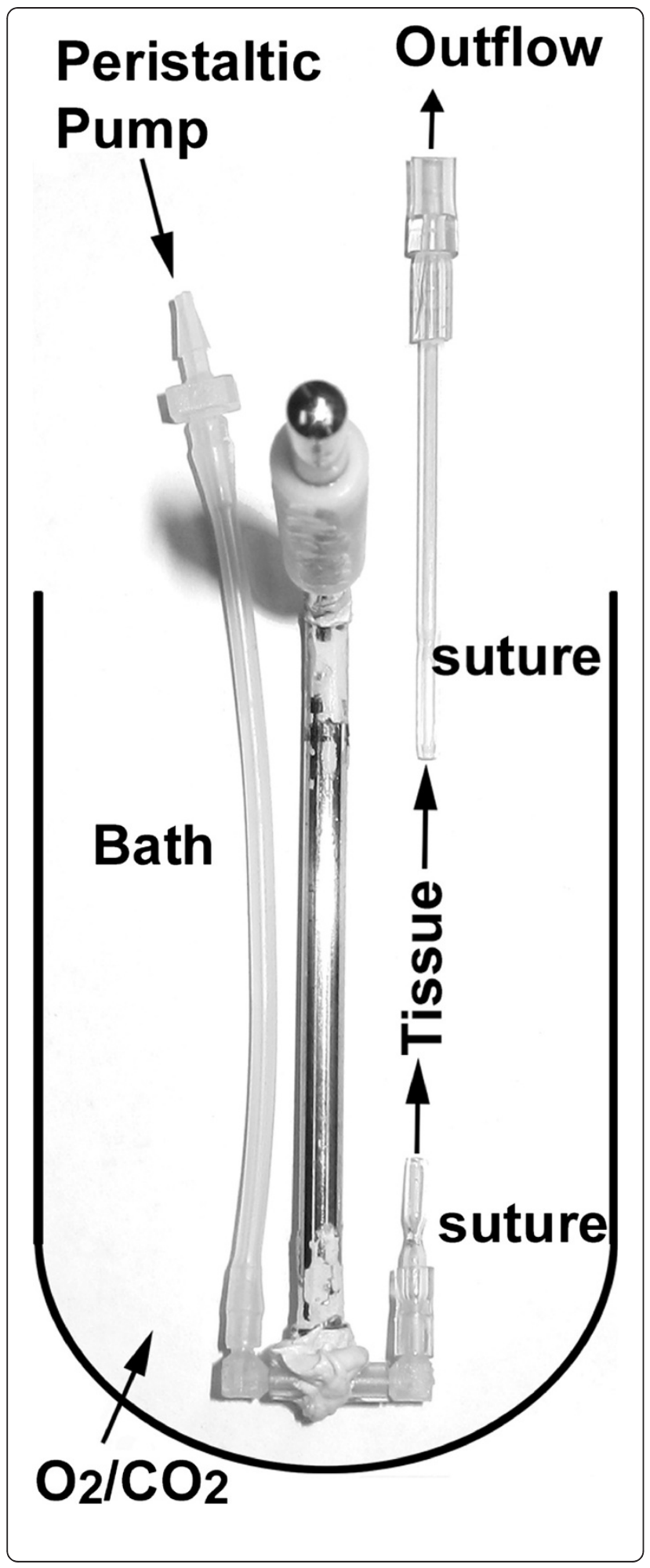

Figure 1 Custom tissue holder for organ bath perfusion studies. A stainless steel tissue holder was modified to hold a 4-5 cm segment of small intestine. The tissue was attached to the fire-polished glass capillaries with sutures at either end. The assembly was then placed in the $37^{\circ} \mathrm{C}$ thermostated organ bath which was filled with bicarbonate buffered Ringer's solution and continuously gassed with $95 \% \mathrm{O}_{2} / 5 \% \mathrm{CO}_{2}$. The tissue was perfused with PBS using a peristaltic pump at a flow rate of $\sim 0.2 \mathrm{~mL}$ min-1. The outflow was collected at 5 min intervals for the 1 st 30 min (equilibration) followed by addition of stimulus and collection of outflow at 3 min intervals (stimulated).

by periodic acid-Schiffs base dot-blot assay, using purified pig gastric mucin as a standard (see Methods). An example of the dot-blot of the dilution series of pig gastric mucin standards used is shown in Figure 2A. The intensity of a serial 2-fold dilution series of mucin from $125 \mu \mathrm{g}$ $0.12 \mu \mathrm{g}$ shows that mucin is detectable down to $\sim 1 \mu \mathrm{g}$ in a $50 \mu \mathrm{L}$ aliquot of perfusate outflow (Figure 2A). When the data are analyzed using standard curve analysis software (SigmaPlot) the nonlinear regression indicates a very good fit $\left(R^{2}=0.997\right)$ (Figure 2B).

As a positive control, the known mucin secretagogue $\mathrm{PGE}_{2}$ [4] was used. Examples from three independent intestinal preparations are shown in Figure 2C. There is variable mucin release during the equilibration period which becomes uniformly low during the final $10 \mathrm{~min}$ of equilibration. Upon addition of $\mathrm{PGE}_{2}$, there is an increase in mucin release whose timing is somewhat variable preparation-to-preparation (Figure $2 \mathrm{C}$ ). Therefore, the area under the curve was calculated, divided by the 30 min stimulation period, and mucin release is expressed as $\mu \mathrm{g}$ mucin $\min ^{-1} \mathrm{~g}^{-1}$ tissue, as shown in Figure 3.

There is disagreement in the literature as to the membrane surface where lubiprostone acts. In some experiments, it was reported that lubiprostone acted when applied to the apical surface of epithelia [1,5] and in others when it was applied basolaterally [6]. Therefore, we tested application of lubiprostone to either surface. When applied to the luminal surface by addition to the perfusate solution, lubiprostone $(1 \mu \mathrm{M})$ had no effect on mucin release (Figure 3A). Similar to luminal lubiprostone, luminal application of $\mathrm{PGE}_{2}(1 \mu \mathrm{M})$ also had no effect on mucin release (data not shown).

We next tested the effect on mucin release of lubiprostone added to the serosal surface (to the bath). For comparison, we used $\mathrm{PGE}_{2}$. As shown in Figure 3B, both $\operatorname{PGE}_{2}(1 \mu \mathrm{M})$ and lubiprostone $(1 \mu \mathrm{M})$ stimulated mucin release. $\mathrm{PGE}_{2}$ increased the rate of mucin release to $\sim 400 \%$ that of the unstimulated (equilibration) rate (Figure 3B). Lubiprostone also stimulated mucin release to over $300 \%$ that of the unstimulated rate (Figure 3B). The difference in stimulation of mucin release between $\mathrm{PGE}_{2}$ and lubiprostone was not statistically significant. 


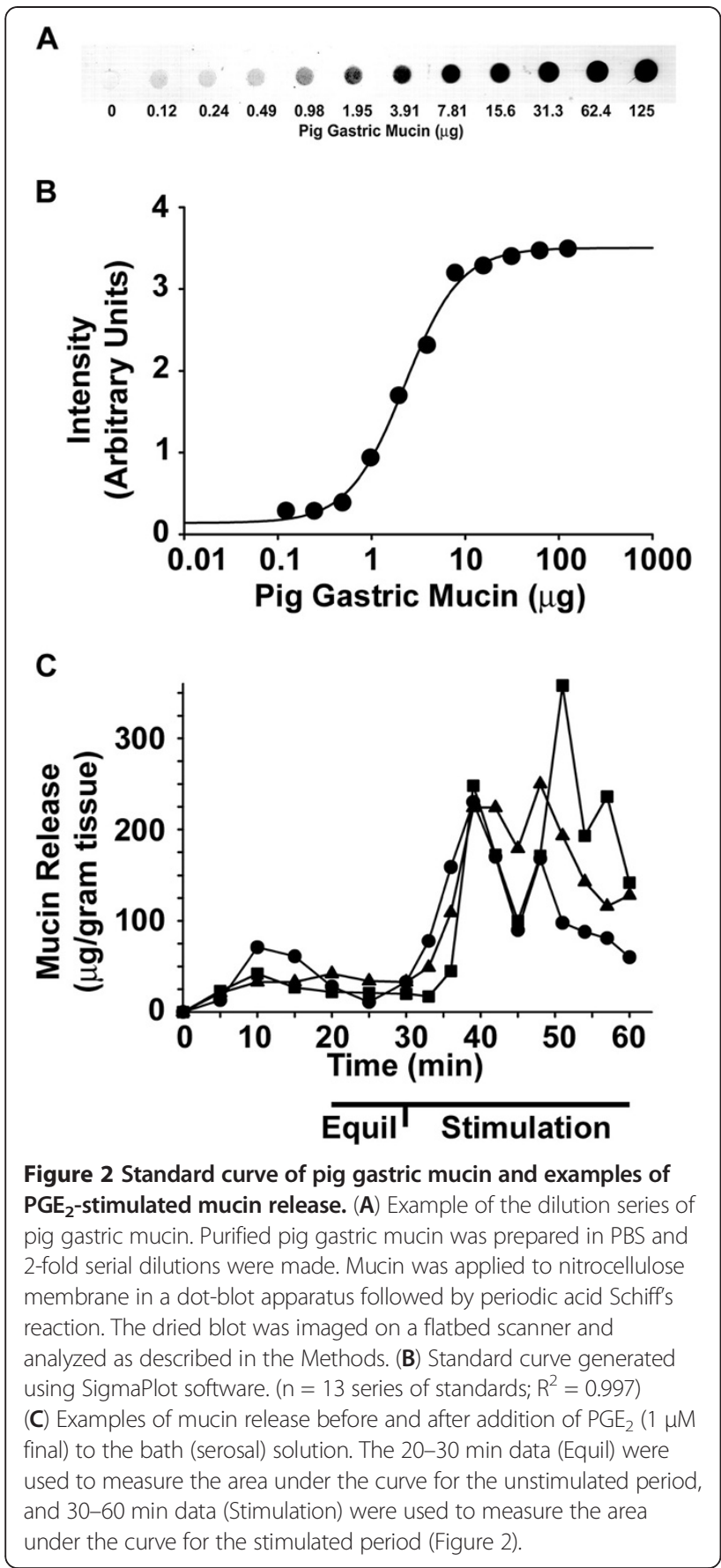

Because lubiprostone also stimulates bicarbonate-rich fluid secretion in the small intestine [7], it is likely that this effect of lubiprostone facilitates solubilization of exocytosed goblet cell mucin and its expansion to mucus. It has been shown that co-secretion of bicarbonate through a CFTR-dependent pathway is crucial for correct expansion of exocytosed mucins $[4,8]$. Since lubiprostone also activates CFTR-dependent bicarbonate secretion, mucin release and bicarbonate will be simultaneously stimulated by lubiprostone.

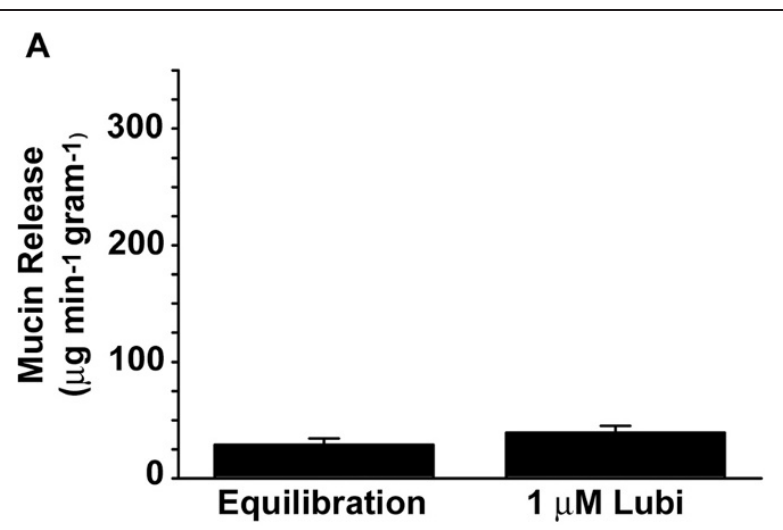

B

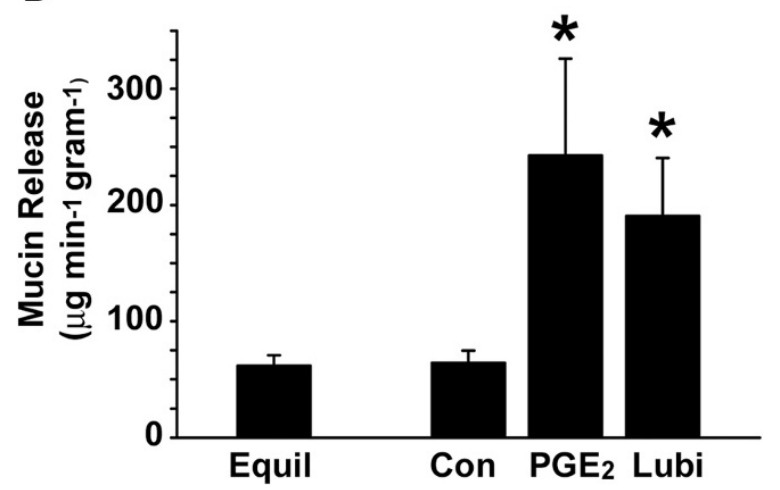

Figure 3 Effect of lubiprostone on intestinal mucin release.

(A) Luminal Lubiprostone. Lubiprostone (1 $\mu \mathrm{M}$ final) was added to the perfusate (luminal) solution after a 30 min equilibration period. The areas under the curves for 20-30 min data (Equilibration) and 3060 min data (1 $\mu \mathrm{M}$ Lubiprostone) were measured and divided by the time period to determine the rates of mucin release. ( $n=2$ intestinal segments) (B) Serosal PGE 2 , Lubiprostone. Vehicle (Control), $\mathrm{PGE}_{2}$ (1 $\mu \mathrm{M}$ final), or lubiprostone (Lubi, $1 \mu \mathrm{M}$ final) was added to the bath (serosal) solution after a 30 min equilibration period. The areas under the curves for 20-30 min data (Equilibration; $n=26$ intestinal segments) and 30-60 min data (Control unstimulated, $n=10 ; \mathrm{PGE}_{2}$, $n=9$; lubiprostone, $n=7$ ) were measured and divided by the time period to determine the rates of mucin release. (*) $p<0.05$ vs Control.

After this study was submitted, a report was published investigating the effects of lubiprostone stimulation in intestinal loop preparations of rat intestines and ex vivo human colonic samples [9]. They showed that lubiprostone caused a coordinated redistribution of several apical and basolateral ion transporters between cytoplasmic vesicles and the plasma membrane that collectively would support secretion at the same time as suppressing absorption, in villi of the small intestine and in colonic crypts. They also quantified mucin granule exocytosis by morphometric histological analyses and showed that lubiprostone caused depletion of goblet cells mucin granules in both small and large intestine. Our results that lubiprostone stimulates mucin release ex vivo from the mouse small intestine are in agreement with the results of this study. 


\section{Conclusions}

The results of this study support the idea that lubiprostone has prostaglandin-like actions on the intestine, which includes stimulation of mucin release. It remains to be determined which prostaglandin receptor(s) is/are activated by lubiprostone in the stimulation of mucin exocytosis by small intestinal goblet cells. It is known that mucin exocytosis and bicarbonate-rich fluid secretion are tightly coupled in the intestine [10] and that fluid secretion is impaired in EP3 $\mathrm{PGE}_{2}$ receptor knockout mice [11]. However, in human duodenum, fluid secretion can be stimulated by an EP4 selective agonist [12] and an EP4 antagonist blocks bicarbonate secretion in rat duodenum [7], making the EP4 receptor a likely candidate for mediating lubiprostone's effects on mucin release. Regardless of which prostaglandin receptor is involved, stimulation of mucin release by lubiprostone may be protective in gastrointestinal conditions where loss of mucus is believed to contribute to pathogenesis [13]. Thus, in addition to chronic constipation, there is greater potential for the therapeutic applications of lubiprostone.

\section{Abbreviations}

CF: Cystic fibrosis; CFTR: Cystic fibrosis transmembrane conductance regulator; PBS: Phosphate buffered saline; $\mathrm{PGE}_{2}$ : Prostaglandin E2.

\section{Competing interests}

Support was provided by grant MSA-LUB-118 from Takeda Pharmaceuticals U.S.A., Inc. Takeda had no input into the design, execution, or data analysis. Takeda Pharmaceuticals is distributing the substance lubiprostone investigated in this study.

\section{Authors' contributions}

RCD performed the experiments, analyzed the data, and wrote the manuscript

\section{Acknowledgements}

I thank Drs. Ning Yang and Paul Quinton for advice setting up the perfusion system and for supplying the fire polished glass capillaries.

Received: 8 May 2012 Accepted: 26 October 2012

Published: 6 November 2012

\section{References}

1. Cuppoletti J, Malinowska DH, Tewari KP, Li QJ, Sherry AM, Patchen ML, Ueno R: SPI-0211 activates T84 cell chloride transport and recombinant human CIC-2 chloride currents. Am J Physio/ Cell Physiol 2004, 287:C1173-C1183. PM:15213059.

2. Bijvelds MJ, Bot AG, Escher JC, De Jonge HR: Activation of intestinal $\mathrm{Cl}$ - secretion by lubiprostone requires the Cystic Fibrosis Transmembrane conductance Regulator. Gastroenterology 2009, 137:976-985. PM:19454284.

3. De Lisle RC, Mueller R, Roach E: Lubiprostone ameliorates the cystic fibrosis mouse intestinal phenotype. BMC Gastroenterol 2010, 10:107. PM:20843337.

4. Garcia MAS, Yang N, Quinton PM, Garcia MAS, Yang N, Quinton PM: Normal mouse intestinal mucus release requires cystic fibrosis transmembrane regulator-dependent bicarbonate secretion. J Clin Invest 2009, 119:2613-2622. PM:19726884.

5. Bao HF, Liu L, Self J, Duke BJ, Ueno R, Eaton DC: A Synthetic Prostone Activates Apical Chloride Channels in A6 Epithelial Cells. Am J Physiol Gastrointest Liver Physiol 2008, 295:G234-251G. PM:18511742.

6. Sheng YH, Hasnain SZ, Png CW, McGuckin MA, Linden SK: Techniques for assessment of interactions of mucins with microbes and parasites in vitro and in vivo. Methods Mol Biol 2012, 842:297-312. PM:22259144.
7. Mizumori M, Akiba Y, Kaunitz JD: Lubiprostone stimulates duodenal bicarbonate secretion in rats. Dig Dis Sci 2009, 54:2063-2069. PM:19657734.

8. Chen EY, Yang N, Quinton PM, Chin WC: A New Role for Bicarbonate in Mucus Formation. Am J Physiol Lung Cell Mol Physiol 2010, 299:L542-L549. PM:20693315.

9. Jakab RL, Collaco AM, Ameen NA: Lubiprostone Targets Prostanoid Signaling and Promotes Ion Transporter Trafficking, Mucus Exocytosis, and Contractility. Dig Dis Sci 2012, PM:22923315.

10. Allen A, Flemstrom G: Gastroduodenal mucus bicarbonate barrier: protection against acid and pepsin. Am J Physiol Cell Physiol 2005, 288:C1-19. PM:15591243.

11. Takeuchi K, Koyama M, Hayashi S, Aihara E: Prostaglandin EP receptor subtypes involved in regulating $\mathrm{HCO}(3)(-)$ secretion from gastroduodenal mucosa. Curr Pharm Des 2010, 16:1241-1251. PM:20166995.

12. Larsen $\mathrm{R}$, Hansen MB, Bindslev N: Duodenal secretion in humans mediated by the EP4 receptor subtype. Acta Physio/ Scand 2005, 185:133-140. PM: 16168007.

13. Johansson ME, Larsson JM, Hansson GC: The two mucus layers of colon are organized by the MUC2 mucin, whereas the outer layer is a legislator of host-microbial interactions. Proc Natl Acad Sci U S A 2011 108(1):4659-4665. PM:20615996.

doi:10.1186/1471-230X-12-156

Cite this article as: De Lisle: Lubiprostone stimulates small intestinal mucin release. BMC Gastroenterology 2012 12:156.

\section{Submit your next manuscript to BioMed Central and take full advantage of:}

- Convenient online submission

- Thorough peer review

- No space constraints or color figure charges

- Immediate publication on acceptance

- Inclusion in PubMed, CAS, Scopus and Google Scholar

- Research which is freely available for redistribution 